\title{
Anesthetic Challenges in the Management of Intracranial Aneurysm Clipping in a Patient with Hypertrophic Cardiomyopathy
}

\author{
Sakshi Duggal' \\ ${ }^{1}$ Department of Anaesthesiology and Intensive Care, G.B. Pant \\ Institute of Postgraduate Medical Education and Research, \\ New Delhi, India \\ 2Department of Anaesthesiology and Intensive Care, \\ Neuroanaesthesia Unit, G.B. Pant Institute of Postgraduate \\ Medical Education and Research, New Delhi, India
}

\author{
Nilima Das ${ }^{1}$
}

J Neuroanaesthesiol Crit Care 2022;9:38-40.

\author{
Address for correspondence Priyanka Khurana, MD, Department \\ of Anaesthesiology and Intensive Care, Neuroanaesthesia Unit, \\ G.B. Pant Institute of Postgraduate Medical Education and Research, \\ 1, Jawahar Lal Nehru Marg, New Delhi 110002, India \\ (e-mail: dr_priyankamadan@hotmail.com).
}

\begin{abstract}
Keywords

- hypertrophic cardiomyopathy

- intracranial aneurysm

- anesthesia
\end{abstract}

\section{Introduction}

Anesthesia for intracranial aneurysm surgeries is challenging due to complications such as hemorrhage, vasospasm, cerebral ischemia, and cardiac dysfunction. ${ }^{1}$ This risk increases multifold in the presence of a coexistent cardiac disorder such as hypertrophic cardiomyopathy (HCM), which may precipitate life-threatening complications such as arrhythmias, congestive heart failure (CHF) and even death. ${ }^{2}$ Anesthetic management of such highrisk comorbidities is troublesome and limited literature is available in this context. ${ }^{3,4}$

We describe the perioperative management of a patient with HCM undergoing emergency anterior communicating artery (ACOM) aneurysm clipping and discuss the pertinent anesthetic concerns.

published online November 19, 2020
DOI https://doi.org/ $10.1055 / \mathrm{s}-0040-1716425$ ISSN 2348-0548.

\section{Case Report}

A 45 -year-old, $50 \mathrm{~kg}$, female presented with a history of severe headache for 2 days followed by altered sensorium. She had no other significant history suggesting cardiac or other comorbidities. On evaluation, she was drowsy but responsive to commands (Glasgow coma scale-E3V5M6) and no neurological deficits. Computed tomography revealed subarachnoid hemorrhage (SAH) in the anterior interhemispheric fissure (size $<1 \mathrm{~mm}$ ) and ACOM aneurysm on angiography. Blood investigations, electrocardiogram, and chest X-ray were normal. Two-dimensional echocardiography revealed coincidental features of HCM with basal septal hypertrophy, systolic anterior motion (SAM) of anterior mitral valve leaflet, moderate diastolic dysfunction, and ejection fraction $60 \%$. (c) 2020. Indian Society of Neuroanaesthesiology and Critical Care. All rights reserved.

This is an open access article published by Thieme under the terms of the Creative Commons Attribution-NonDerivative-NonCommercial-License, permitting copying and reproduction so long as the original work is given appropriate credit. Contents may not be used for commercial purposes, or adapted, remixed, transformed or built upon. (https://creativecommons.org/licenses/by-nc-nd/4.0/)

Thieme Medical and Scientific Publishers Pvt. Ltd., A-12, 2nd Floor, Sector 2, Noida-201301 UP, India 
Patient was posted for emergency craniotomy and aneurysmal clipping within 6 hours of presentation under highrisk consent. Intravenous maintenance fluid at $80 \mathrm{~mL} / \mathrm{h}$ was started preoperatively. Operative room readiness was ensured with pressure bags, vasopressors (phenylephrine, noradrenaline), availability of blood products, and defibrillator. Standard neurosurgical monitoring along with arterial blood pressure (ABP) was instituted. Her heart rate (HR) was $80 \mathrm{bpm}$ and ABP was 156/94 mm Hg. Dexmedetomidine infusion was started at $0.6 \mu \mathrm{g} / \mathrm{kg} / \mathrm{h}$; no bolus was given. After 20 minutes, general anesthesia was induced with $1 \mathrm{mg}$ midazolam, $100 \mu \mathrm{g}$ fentanyl, $200 \mathrm{mg}$ thiopentone, and $6 \mathrm{mg}$ vecuronium; postinduction vitals remained stable with $A B P$ : 128/84 mm Hg and HR: 86 bpm. Controlled ventilation was initiated and right jugular vein was cannulated for central venous pressure (CVP) monitoring. Baseline CVP of $8 \mathrm{cmH}_{2} \mathrm{O}$ and pulse pressure variation (PPV) of 6 were recorded. Anesthesia was maintained with sevoflurane (2\%), vecuronium infusion $(0.1 \mathrm{mg} / \mathrm{kg} / \mathrm{h})$, and fentanyl boluses $(2 \mu \mathrm{g} / \mathrm{kg}$ hourly). Dexmedetomidine infusion $(0.3-0.6 \mu \mathrm{g} / \mathrm{kg} / \mathrm{h})$ and intravenous fluid were titrated to maintain target hemodynamics (HR: 60-70 bpm, BP: 120-140/80-90 mm Hg, CVP: 8-10 $\mathrm{cmH}_{2} \mathrm{O}$, PPV: 4-6). Single permanent clip was placed with temporary clipping time of 45 seconds. The intraoperative period was uneventful with no cardiac or neurological complications. On completion of surgery, dexmedetomidine infusion was stopped and anesthesia was reversed. Trachea was extubated with no cough, emetic, painful, or hypertensive stress response. Nimodipine infusion $(0.5 \mathrm{mg} /$ hour $)$ was started along with noradrenaline infusion $(0.05 \mu \mathrm{g} / \mathrm{kg} / \mathrm{min})$ keeping systolic BP around 150 to $160 \mathrm{~mm} \mathrm{Hg}$. Intravenous fluid was titrated to maintain CVP of 6 to $8 \mathrm{cmH}_{2} \mathrm{O}$ and urine output of $0.5 \mathrm{~mL} / \mathrm{kg} / \mathrm{h}$. Postoperative cardiac consultation and echocardiography were unremarkable. Further stay was uneventful and patient was discharged on 12th day after surgery.

\section{Discussion}

HCM is a genetic cardiac disorder with a prevalence of $0.2 \%$. However, only $0.03 \%$ of patients are symptomatic and majority are diagnosed incidentally as in our case. ${ }^{5}$ It involves asymmetrical hypertrophy of left ventricle (LV) with or without SAM of mitral valve leading to mechanical or dynamic left ventricular outflow tract obstruction (LVOTO). ${ }^{6}$ The hypertrophied LV results in diastolic dysfunction, atrial fibrillation, CHF and death. ${ }^{2}$ Patients are often managed medically using negative inotropic agents such as beta-blockers, calcium channel blockers, and disopyramide. The aim of treatment is to reduce or eliminate the LVOT gradient, ultimately reducing incidence of dynamic obstruction and fatal dysrhythmias. Other invasive methods of management are alcohol septal ablation of selective septal coronary branches and surgical myomectomy. ${ }^{6}$ Up to $60 \%$ higher incidence of perioperative cardiac events and $4.2 \%$ higher mortality have been reported in patients with HCM undergoing noncardiac surgeries than their matched controls. ${ }^{2,6}$
In a patient with SAH due to ruptured aneurysm and HCM, a thorough preoperative history and physical examination should aim to rule out arrhythmia and CHF. Arrhythmias/ myocardial dysfunction due to HCM should be differentiated from SAH-induced changes and optimized. Beta-blockers or calcium channel blockers should be started ideally a month or at least a week before surgery to achieve optimum hemodynamics with a target HR of 55 to $70 \mathrm{bpm} .^{7}$ This might not always be possible due to incidental diagnosis and emergent surgery as in our case. Premedication with chronotropic agents such as atropine and glycopyrrolate should be avoided. ${ }^{6}$ Preoperative fluids should be slow and titrated to optimize intravascular volume while avoiding $\mathrm{CHF}^{6}{ }^{6}$

Various perioperative factors such as tachycardia, Valsalva maneuver, laryngoscopy, intubation, decrease in preload and afterload, and inotropic or chronotropic agents might precipitate LVOTO in HCM leading to hemodynamic complications. ${ }^{8}$ Thus, maintenance of sinus rhythm with target HR 60 to $70 \mathrm{bpm}$, careful drug titration, and goal-directed fluid therapy are essential. ${ }^{7}$ Vasopressors that relieve dynamic LVOTO such as phenylephrine and noradrenaline are recommended in HCM, while inotropes such as dopamine, dobutamine, epinephrine, and isoproterenol that worsen LVOTO should be avoided. ${ }^{6}$ Vigilant monitoring with ABP, CVP, PPV, blood loss, and urine output should be instituted for quick action on hypotension and other adverse events. ${ }^{6}$ Transesophageal echocardiography is considered ideal to check for LV filling and LVOTO. ${ }^{8}$ However, its availability and skill among anesthetists remain a limitation.

Strict postoperative vigilance for rebleeding, vasospasm, or cardiac decompensation is essential. Nimodipine infusion after aneurysmal surgeries for prevention of vasospasm may lead to hypotension. This can be avoided by coadministering vasopressors that maintain afterload and prevent LVOTO. ${ }^{1}$ Phosphodiesterase- 3 inhibitors for vasospasm are not suitable in HCM because of their inotropic and vasodilating properties. Intra-arterial verapamil, papaverine, or balloon angioplasty should be preferred instead. ${ }^{9}$

One major consideration in HCM is prevention of sympathetic stimulation due to laryngoscopy, intubation, or surgical incision. This is also beneficial for aneurysmal procedures so as to prevent rupture or rebleeding. Choice of drugs to mitigate this stress response in HCM is limited., ${ }^{3,4}$ Dexmedetomidine has emerged as an excellent anesthetic adjuvant for aneurysmal surgeries due to its ability to attenuate stress response and maintain stable hemodynamics perioperatively..$^{10}$ Its opioid sparing and antiemetic action ensures rapid yet smooth emergence from anesthesia allowing early assessment after neurosurgery. ${ }^{10}$ Its sympatholytic, negative chronotropic, and antinociceptive properties prevent precipitation of LVOTO in HCM by decreasing tachycardiac responses at critical points. Hypotension and bradycardia can be prevented by skipping the loading dose. ${ }^{4}$ Single case series documents use of dexmedetomidine in two pediatric patients with HCM undergoing noncardiac surgery. ${ }^{4}$ Its use in adults with HCM undergoing aneurysmal surgery has not been reported yet, making our case first of a kind.

Thus, intracranial aneurysm in patients with HCM entails unique anesthetic challenge that can be overcome by 
meticulous planning, strict vigilance, and careful drug selection. Dexmedetomidine has proven to be a useful anesthetic adjuvant in the presence of such coexisting disorders.

\section{Conflict of Interest}

None declared.

\section{References}

1 Abd-Elsayed AA, Wehby AS, Farag E. Anesthetic management of patients with intracranial aneurysms. Ochsner J 2014;14(3):418-425

2 Hreybe H, Zahid M, Sonel A, Good CB, Shaver J, Saba S. Noncardiac surgery and the risk of death and other cardiovascular events in patients with hypertrophic cardiomyopathy. Clin Cardiol 2006;29(2):65-68

3 Edmends S, Ghosh S. Hypertrophic obstructive cardiomyopathy complicating surgery for cerebral artery aneurysm clipping. Anaesthesia 1994;49(7):608-609

4 Karuppiah S, Syed A, Naguib A, Tobias JD. Perioperative management of two pediatric patients with hypertrophic cardiomyopathy undergoing minimally invasive surgical procedures. J Med Cases 2016;7(4):115-119
5 Husser D, Ueberham L, Jacob J, et al. Prevalence of clinically apparent hypertrophic cardiomyopathy in Germany-an analysis of over 5 million patients. PLoS One 2018;13(5):e0196612

6 Hensley N, Dietrich J, Nyhan D, Mitter N, Yee MS, Brady M. Hypertrophic cardiomyopathy: a review. Anesth Analg 2015;120(3):554-569

7 Gersh BJ, Maron BJ, Bonow RO, et al. 2011 ACCF/AHA guideline for the diagnosis and treatment of hypertrophic cardiomyopathy: a report of the American College of Cardiology Foundation/American Heart Association Task Force on Practice Guidelines. J Thorac Cardiovasc Surg 2011;124:e783-e831

8 Sahoo RK, Dash SK, Raut PS, Badole UR, Upasani CB. Perioperative anesthetic management of patients with hypertrophic cardiomyopathy for noncardiac surgery: a case series. Ann Card Anaesth 2010;13(3):253-256

9 Fraticelli AT, Cholley BP, Losser MR. Saint Maurice JP, Payen D. Milrinone for the treatment of cerebral vasospasm after aneurysmal subarachnoid hemorrhage. Stroke 2008;39(3):893-898

10 Peng K, Wu S, Liu H, Ji F. Dexmedetomidine as an anesthetic adjuvant for intracranial procedures: meta-analysis of randomized controlled trials. J Clin Neurosci 2014;21(11):1951-1958 